\title{
ВЛИЯНИЕ ЭТАПА РАЗВИТИЯ ПСИХОЛОГИЧЕСКОЙ ТРАВМЫ НА ОСОБЕННОСТИ ЛИЧНОСТИ, У ЖЕНЩИН, ПОДВЕРГШИХСЯ НАСИЛИЮ В СЕМЬЕ
}

\section{INFLUENCE OF PSYCHOLOGICAL TRAUMA DEVELOPMENT STAGE ON PERSONAL CHARACTERISTICS IN WOMEN EXPERIENCING DOMESTIC VIOLENCE \\ O. Tausinova}

Summary: Purpose: the article deals with the features of psychological trauma development on the personality traits of women who have experienced domestic violence, analyzes the features of psychological trauma.

Methods: in the course of the study, we used the following methods: a clinical questionnaire for identifying and evaluating neurotic States (authors - K.K. Yakhin, D.M. Mendelevich), a test of neuropsychic adaptation (I.N. Gurvich), the V.M. Bekhterev research Institute, a symptomatic questionnaire SCL-90-R Derogatis scale, Q sorting, a thematic apperceptive questionnaire TAT. SPSS, the Mann Whitney test, was used as a statistical data processing program.

Results: in the course of the study, there was a tendency for women who are at the stage of assimilation of traumatic experiences to have a high level of asthenia and neurotic depression. Women tend to avoid leadership, the topic of relationships with the opposite sex, at this stage becomes significant, but remains painted in dark tones. Women of all three groups showed an attitude to themselves, an interest in their personality, a high level of neuroticism, a desire for dependence and a tendency to avoid struggle.

Conclusions: thus, we observe significant differences in the features of trauma development at different stages, which suggests that the strategy for working with these women should differ, depending on the duration of the traumatic event.

Keywords: domestic violence, psychological trauma, Psychotrauma, trauma experience, stages of traumatization, domestic violence.
Таусинова Ольга Константиновна

Аспирант, ФГБОУ ВО «Красноярский государственный медицинский университет имени профессора

В.Ф. Войно-Ясенецкого» Министерства здравоохранения Российской Федерации rector@krasgmu.ru

Аннотация: Цель: в статье рассматриваются особенности развития психологической травмы на особенности личности, у женщин, переживших насилие в семье, анализируется особенности психологической травмы.

Методы: в процессе исследования нами использовались следующие методики: клинический опросник для выявления и оценки невротических состояний (авторы - К.К. Яхин, Д.М. Менделевич), тест нервно-психической адаптации (И.Н. Гурвич), НИИ им. В.М. Бехтерева, симптоматический опросник SCL-90-R Шкала Дерогатиса, Q сортировка, тематический апперцептивный опросник ТАТ. В качестве программы обработки статистических данных была использована SPSS, критерий Манна Уитни.

Результаты: в процессе исследования была замечена тенденция женщин, находящихся на этапе ассимиляции травмирующего опыта характерен высокий уровень астении и невротической депрессии. Женщины имеют стремятся избежать лидерства, тема отношений с противоположным полов, на данном этапе становится значимой, но остается окрашенной в мрачные тона. Отношение к себе, заинтересованность в своей личности, наличие высокого уровня невротизации, стремление к зависимости и склонности к избеганию борьбы проявлялось у женщин всех трех групп.

Выводы: таким образом, мы наблюдаем значимые различия в особенностях развития травмы на различных этапах, что предполагает, что стратегия работы с данными женщинами должна различаться, в зависимости от давности травматического события.

Ключевые слова: насилие в семье, психологическая травма, психотравма, переживание травмы, этапы травматизации, домашнее насилие.

ской травмы [2].

Мы рассматриваем психологическую травму, это некую угрозу целостности личности, или целостности близких, физическую или психологическую. Дмитриева Н.В., Козырева Т.С., Перевозкина Ю.М. [3] отмечают, что, оказавшись в ситуации угрозы целостности невозможно, не быть травмированным, при этом различаются реакции на событие. Oram S., Khalifeh H., Howard L.M. описывают в своем труде, что каким-то потерпевшим удается ассимилировать опыт, и продолжать нормальную жизнедеятельность, а кто-то остается в глубоком 
кризисном состоянии, либо может проживать посттравматическое расстройство личности [4].

Азарных Т.Д. указывает на то, что женщины, которые совершают попытку завершить отношения с насильником, в 80 \% случаев возвращаются обратно. Они способны игнорировать агрессивную сторону насильника, а значит существующую опасность, либо они боятся вызывать ещё большую агрессию [5]. Moreira P.S., Cloninger CR, Rocha MJ, Ferreira N, Oliveira J, Gonçalves D.M. отмечают, что часто психические состояния, которые формируются у женщины вследствие длительного домашнего насилия становится более выраженными, и самопомощи недостаточно, женщина нуждается в специализированной помощи [6].

Исаева Э.Г. Сутаева А.Р. указывают, что с точки зрения работы с психологической травмой огромное значение для работы и реабилитации имеют сроки давности травмы. Не умаляя её значимости травмы, важно сказать, что у психологических травм не бывает срока давности [7].

\section{Материалы и методы}

В исследовании учувствовало три группы респондентов, 30 человек, в каждой, все испытуемые были женщинами в возрасте от 20-и лет до 36-и, средний возраст 32,6 лет, средний срок брака 5,4 года, все женщины работают и имеют детей.

1. Первая группа, состояла из женщин, остающихся в травматической ситуации. Проживающих с мужем или сожителем и находящиеся с ним в сложных и насильственных отношениях.

2. Вторая группа, состояла из женщин, оказавшихся в безопасном месте, после завершения травмы. Данная группа женщин проживали не более двух месяцев не на территории мужа или сожителя, у родителей, либо арендовали квартиру. Отношения были завершены.

3. Третья группа, состояла из женщин, находящихся на этапе ассимиляции травмирующего опыта, и находящиеся в безопасном месте более полу года.

В процессе исследования нами использовались следующие методики: клинический опросник для выявления и оценки невротических состояний (авторы - К.К. Яхин, Д.М. Менделевич), тест нервно-психической адаптации (И.Н. Гурвич), НИИ им. В.М. Бехтерева, симптоматический опросник SCL-90-R Шкала Дерогатиса, Q сортировка, тематический апперцептивный опросник ТАТ. В качестве программы обработки статистических данных была использована SPSS, критерий Манна Уитни.

\section{^итературный обзор}

Шведский психиатр Johan Cullberg, в своей книге Creating Crisis (1992) выделил следующие этапы развития травмы:

1. Шоковая фаза - продолжительность от нескольких часов до нескольких дней с момента травмы.

2. Фаза реакции длится - 2-4 месяца.

3. Фаза возврата к действительности - начинается после 4-го месяца с момента травмы, продолжительность около 2-х месяцев.

4. Фаза реабилитации - начало этой фазы через полгода после травмы [8].

Ясенка Преград - автор и руководитель программы ЮНИСЕФ «Остановить насилие среди детей» (программой охвачено более 300 школ и 150000 учеников), приводит следующие фазы:

1. Пока травма происходит. Фаза травматизации, фаза, которая может длится длительно, если речь идет, например, о систематическом насилии, либо быстро, стихийные бедствия.

2. Сразу после травмы. Травма завершилась, и женщина попала в безопасное место. Т.е. чаще всего это происходит после разрыва отношений, либо при смене места жительства.

3. Позже. Через определенное время происходит этап ассимиляции опыта.

Как отмечают Niolon P.H, Kearns M, Dills J, Rambo K, Irving S, Armstead T, Gilbert L., Преград Я. указывает, что очень важно, что б участники психологических групп реабилитации имели похожий опыт и давность травмы, так как женщины, пережившие насилие, часто переполнены эмоциями, и не могут слушать других участников, а противоречивые переживания могут привести к ретравматизации [9].

Judith Herman в труде Trauma and Recovery: The Aftermath of Violence (2015) соглашается с Преград Я. в плане описания фаз травматизации, а так же приводит, подробный анализ психологической реабилитации лиц переживших травматическую ситуацию [10].

По мнению Madalena, M. , Carvalho, L.F. , \& Falcke, D. существует высокий уровень актуальности поддержки, реабилитации и работы с женщинами, пережившими насилие, отсутствует достаточное количество исследований, посвященных специфике работы с женщинами, пережившими насилие в семье, с точки зрения динамики переживаний после траматической ситуации, а это является критически важным аспектом, в разработке программ реабилитации пострадавших, и в последствии их успешной социализации [11, 12].

Данное противоречие обусловило выбранное нами направление работы.

Цель исследования заключается в эмпирическом и теоретическом анализе влияние этапа развития психологической травмы на особенности личности, у женщин, 
переживших насилие в семье.

Задачи исследования заключались в рассмотрении особенностей влияния психологической травмы на особенности личности у женщин, переживших насилие в семье, подборе методик, организации исследования, а так же сравнительном анализе групп респондентов с точки зрения этапа развития психологической травмы.

\section{Результаты}

По результатам опросника для выявления и оценки невротических состояний (К.К. Яхина, Д.М. Менделевича) были выявлены следующие показатели у женщин, результаты представлены в таблице 1:

Таблица 1.

Исследование оченки невротических состояний (среднее)

\begin{tabular}{|l|c|c|c|c|}
\hline & $\begin{array}{c}\text { Общая } \\
\text { выборка }\end{array}$ & Группа 1 & Группа 2 & Группа 3 \\
\hline Тревога & $-1,974$ & $-0,15$ & 1,25 & 1,53 \\
\hline $\begin{array}{l}\text { Невротическая } \\
\text { депрессия }\end{array}$ & $-2,54$ & 0,34 & 1,12 & 0,86 \\
\hline Астения & 0,57 & $-1,67$ & 0,76 & $-1,04$ \\
\hline $\begin{array}{l}\text { Истерический тип } \\
\text { реагирования }\end{array}$ & 1,71 & 0,98 & 0,34 & 0,28 \\
\hline $\begin{array}{l}\text { Обсессивно- фобические } \\
\text { нарушения }\end{array}$ & 1,32 & 2,21 & 1,70 & 1,84 \\
\hline $\begin{array}{l}\text { Вегетативные } \\
\text { нарушения }\end{array}$ & 0,87 & 0,86 & 1,65 & 1,82 \\
\hline
\end{tabular}

Статистические значимые различия наблюдались по шкалам тревоги депрессии стене между группами 1 и 3.

Далее в таблице представлены группы в зависимости от динамики развития травматического состояния, по результатам теста Тест нервно-психической адаптации (И.Н. Гурвич), НИИ им. В. М. Бехтерева

Таблица 2.

\section{Исследование оценки нервно-психической адаптации (среднее)}

\begin{tabular}{|l|c|c|c|}
\hline & Группа 1 & Группа 2 & Группа 3 \\
\hline Шкала тревоги & $18,5 \pm 5,8$ & $35,6 \pm 7,3$ & $32,4 \pm 7,9$ \\
\hline
\end{tabular}

Результаты группы 2 и 3 относятся к средним значениям и не является низким.

Для того чтобы понять, насколько этап развития травмы может влиять на психическое здоровье, нами было проведено сравнение трех групп по шкалам SCL-90-R.
Таблица 3.

Сравнение показателей по шкалам SCL 90 R (среднее)

\begin{tabular}{|l|c|c|c|}
\hline Подшкалы SCL9OR & Группа 1 & Группа 2 & Группа 3 \\
\hline Соматизация (SOM) & 0,67 & 0,76 & 0,74 \\
\hline $\begin{array}{l}\text { 0бсессивность - компульсивность } \\
\text { (OC) }\end{array}$ & 0,70 & 1,46 & 0,77 \\
\hline Межличностная сензитивность (INT) & 0,67 & 1,41 & 0,73 \\
\hline Депрессия (DEP) & 0,70 & 1,67 & 0,74 \\
\hline Тревожность (ANX) & 0,62 & 1,46 & 0,67 \\
\hline Враждебность (HOS) & 0,60 & 1,10 & 0,66 \\
\hline Фобическая тревожность (PHOB) & 0,30 & 0,64 & 0,37 \\
\hline Паранойяльные симптомы (PAR) & 0,62 & 1,16 & 0,67 \\
\hline Психотизм (PSY) & 0,42 & 0,74 & 0,46 \\
\hline Общий индекс тяжести (GSI) & 0,66 & 1,26 & 0,67 \\
\hline
\end{tabular}

Женщины 2 и 3 группы склонны к развитию обсессивно-компульсивных чёрт, в то время как группа 1 находится в состоянии депрессии.

Таблица 4.

Сравнение показателей по шкалам Q сортировки (среднее)

\begin{tabular}{|l|c|c|c|}
\hline Подшкалы Q сортировки & Группа 1 & Группа 2 & Группа 3 \\
\hline Зависимость & 5,7 & 6,8 & 5,8 \\
\hline Необщительность & 6,2 & 5,8 & 7,9 \\
\hline Избегание борьбы & 6,8 & 8,5 & 8,6 \\
\hline Независимость & 2,2 & 2,6 & 1,7 \\
\hline Общительность & 3,7 & 2,8 & 4,6 \\
\hline Принятие борьбы & 1,7 & 1,9 & 2,7 \\
\hline
\end{tabular}

В целом необходимо заметить, что респондентки трёх групп обладает тенденцией к зависимости, имеет низкую социальную адаптацию, при этом Данные показатели в группе один выражена наиболее ярко.

Рассмотрим результаты традиционного Тематического апперцептивного теста (ТАТ).

Таблица 5.

Контент-анализ рассказов трех групп женщин (\%)

\begin{tabular}{|l|c|c|c|}
\hline Показатель & Группа 1 & Группа 2 & Группа 3 \\
\hline Констатирующий тип изложения & 30,8 & 16,7 & 0,0 \\
\hline Описательный тип изложения & 69,2 & 83,3 & 100,0 \\
\hline $\begin{array}{l}\text { Использование выразительных } \\
\text { средств языка }\end{array}$ & 38,5 & 50,0 & 100,0 \\
\hline Тема сюжета: & 12,0 & 13,1 & 18,9 \\
\hline собственное «Я» & 49,0 & 42,5 & 37,7 \\
\hline $\begin{array}{l}\text { социальные отношения и доминиро- } \\
\text { вание }\end{array}$ & 19,0 & 37,5 & 43,4 \\
\hline отношения спротивоположным полом & & & \\
\hline
\end{tabular}


Как видно из таблицы, 1-я группа гораздо реже, чем 3-я группа, разворачивают целостный рассказ при предъявлении стимульного материала и практически не используют выразительные средства языка ( $<<0,001)$.

В большинстве своем женщины первой и второй группы стремились констатировать ситуацию, описывать ее, не развивая и не углубляясь, даже при поощрении экспериментатора. Женщины группы 1 стремились при этом интерпретировать увиденное, употребляли выразительные средства языка.

Перейдём далее к обсуждению полученных результатов.

\section{ОбсужАение}

Согласно полученным результатом, в группе 1 доминируют болезненные и предболезненное состояние, практически отсутствуют нормативные показатели, в большей степени мы наблюдаем пиковые значения особенно по шкалам «тревоги», «депрессии» и «истерического типа реагирования». Вторая группа более нормативна по показателям, значения в зоне болезни не наблюдаются, однако выражена «астения», «тревога» и «депрессия», а также «истерический тип реагирования». В третьей группе ряд показателей соответствовал нормативным уровнем здоровья, однако также наблюдалось депрессивные состояния. Таким образом, результаты проведенного исследования свидетельствуют о наличии наибольшего уровня невротизации в группе 1.

Уровень нервно-психической адаптации в группах 2 и 3 статистически значимо различаются с результатами группы 1. Что любопытно, наиболее высокий уровень нервно-психической адаптации достигает вторая группа, что может говорить, о некотором эйфорическом состоянии, после пережитых событий. В последствии уровень нервно-психической адаптации снижается. Уровень социально-психологической адаптированности испытуемых первой группы относится к низким значениям им свойственна патологическая психическая дезадаптация и вероятное болезненное состояние. Показатели обследования группы 3 значительной степени отличается от показателей группы 1, респондентки третий группы имеют менее выраженные психопатологические симптомы. Первая и вторая группа различаются по школам «соматизации», «депрессии» и «психотзма». Вторая и третья группа наиболее различны по шкалам враждебности «психотизма» и «межличностная сензитивность». Таким образом женщины группы 1 имеют явные черты психологического неблагополучия, мы предполагаем, что данные изменения носят приобретённый характер и является в некотором смысле пограничными.

В рассказах женщин первой второй группы наиболее распространённой темой являла систему социальных отношений, и доминирования, в то время как респондентки группы 3 более заинтересованы в теме отношений с противоположным полом. Все три группы редко касались темы собственного «Я» и отношения к себе. Женщины первой группы более фокусировались на теме отношений с другим, а женщины группы 2 и 1 касались темы «плохого будущего», страшных фантазий о том, что может случиться. Женщины группы 3 описывали отношения с противоположным полом в романтическом ключе, при этом их рассказы были полны тревоги. В рассказах группы 1 и 2 наиболее ярко прослеживается темы недостижимой взаимности. Женщины группы 1 говорят о возможности того, что другой человек может измениться.

Таким образом обобщая вышесказанное необходимо заметить, что женщины, которые остаются в травматической ситуации находится в болезненных переживаниях, они астеничны, тревожны и им свойственна депрессивная симптоматика, они теряют интерес к жизни, стремятся избегать борьбы и склонны к зависимым отношениям.

Для женщин, оказавшихся в безопасном месте, после завершения травмы характерен высокий уровень астении и истерического реагирования. Женщинам свойственен высокий уровень нервно-психической адаптации, увеличивается вероятность развития непрерывных, непреодолимых и чуждых «Я» мыслей, импульсов и действий.

Для женщин, находящихся на этапе ассимиляции травмирующего опыта характерен высокий уровень астении и невротической депрессии. Женщины имеют высокие показатели по шкале «обсессивности - компульсивности», Женщины имеют стремление уйти от взаимодействия, сохранить нейтралитет в групповых спорах и конфликтах, избежать лидерства, тема отношений с противоположным полов, на данном этапе становится значимой, но остается окрашенной в мрачные тона.

Отношение к себе, заинтересованность в своей личности, наличие высокого уровня невротизации, стремление к зависимости и склонности к избеганию борьбы проявлялось у женщин всех трех групп.

\section{ЗакАючение}

Таким образом, мы можем заметить тенденцию к изменению переживаний и особенностей развития травматической ситуации, начиная от острого этапа нахождения в травмирующей ситуации, женщины попадая в безопасное место, испытывают временное короткое эйфорическое состояние, но при этом проживают явную тревогу и не имеют достаточно личной энергии к деятельности, что выражается в астеническтих тенденциях. 
На этапе ассимиляции, когда происходит, в некотором роде «сваривание полученного опыта, мы можем замечать, что с одной стороны невротическая симптоматика снижается, но остается мрачные взгляды на будущее, по видимому обусловленные травматической ситуацией, а так же некоторые характерологические особенности, такие как склонность к зависимости. Так же женщины остаются тревожными, не в достаточной степени нерв- но-психически адаптированными.

Таким образом, мы наблюдаем значимые различия в особенностях развития травмы на различных этапах, что предполагает, что стратегия работы с данными женщинами должна различаться, в зависимости от давности травматического события. Данное направление является актуальным, и требует дальнейших научных разработок.

ЛИТЕРАТУРА

1. Rode D., Rode M., Marganski A.J. et al. The Impact of Physical Abuse \& Exposure to Parental IPV on Young Adolescents in Poland: a Clinical Assessment and Comparison of Psychological Outcomes // J Fam Viol. 2019. № 34. P. 435-447. doi.org/10.1007/s10896-019-00036-4

2. Both L.M, Favaretto T.C., Freitas L.H. Cycle of violence in women victims of domestic violence: Qualitative analysis of OPD 2 interview // Brain Behav. 2019 . № 9. P. 1-13. doi.org/10.1002/brb3.1430

3. Дмитриева Н.В., Козырева Т.С., Перевозкина Ю.М. Кризисная идентичность посттравматической личности. Монография. Мин-Во обр. и науки РФ; 2014.

4. Oram S, Khalifeh H, Howard L.M. Violence against women and mental health // Lancet Psychiatry. 2017. № 4. P. 159-170. dx.doi.org/10.1016/. S22150366(16)30261-9

5. Азарных Т.Д. Личностные особенности при посттравматических стрессах // Академический журнал Западной Сибири. 2012. №1. С.33.

6. Moreira P.S., Cloninger C.R., Rocha M.J., Ferreira N., Oliveira J., Gonçalves D.M. The psychometric properties of the Portuguese version of the TCl-R // Psychological Reports. 2017; № 120(6). P. 1178-1199. doi: 10.1177/0033294117711914

7. Исаева Э.Г. Сутаева А.Р. Консультирование травмированной личности // Вестник Университета Российской академии 0бразования. 2016. №4. С.84-93.

8. Cullberg J. Creating Crisis // Acta Psychiatrica Scandinavica. № 84 (3). P. 242-245. doi:10.1111/j.1600-0447.1991.tb03137

9. Niolon P.H, Kearns M., Dills J., Rambo K., Irving S., Armstead T., Gilbert L. Preventing intimate partner violence across the lifespan: a technical package of programs, policies, and practices. National Center for Injury Prevention and Control, Centers for Disease Control and Prevention. c2017. Available at: https://www.cdc.gov/ violenceprevention/pdf/ipv-technicalpackages.pdf Accessed: 8 Mar 2021.

10. Herman J. Group Trauma Treatment in Early Recovery: Promoting Safety and Self-Care. The Guilford Press; 2015.

11. Madalena M., Carvalho L. F., \& Falcke D. Violência conjugal: 0 poder preditivo das experiências na família de origem e das características patológicas da personalidade // Trends in Psychology. 2018. № 26(1), P.75-91. 10.9788/TP2018.1-04Pt

12. Herman J. Trauma and Recovery: The Aftermath of Violence--from Domestic Abuse to Political Terror. The Guilford Press; 2018.

(с) Таусинова Ольга Константиновна (rector@krasgmu.ru). 